
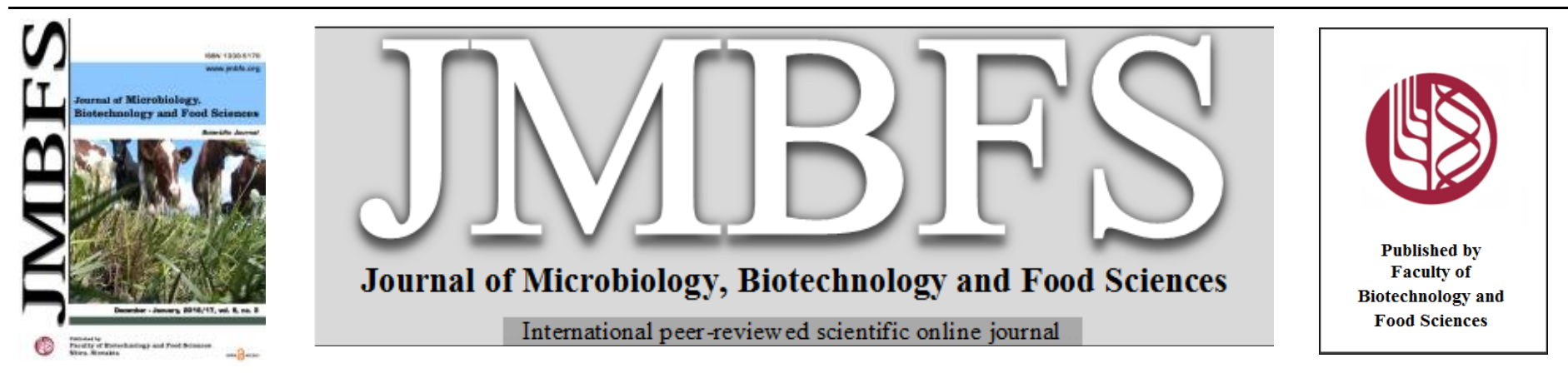

\title{
EVALUATION OF THE IMMUNOGENICITY OF EACH OF L-AMINO OXIDASE- AND L-ASCORBIC ACID- INACTIVATED HEPATITIS A VIRUS IN MICE AS POTENTIAL VACCINE CANDIDATES
}

\author{
Amal Osman Abdullatif ${ }^{1}$, Mahmoud Mohamed Tawfick ${ }^{2,3}$, Abeer Khairy Abdulall ${ }^{1}$, Aly Fahmy Mohamed ${ }^{4}$

\section{Address(es):} \\ ${ }^{1}$ Microbiology and Immunology Department, Faculty of Pharmacy (Girls), Al-Azhar University, Nasr City, Cairo, Egypt. \\ ${ }^{2}$ Microbiology and Immunology Department, Faculty of Pharmacy (Men), Al-Azhar University, Nasr City, Cairo, Egypt. \\ ${ }^{3}$ Microbiology and Immunology Department, Faculty of Pharmacy, October University for Modern Sciences and Arts, $6{ }^{\text {th }}$ October City, Giza, Egypt. \\ ${ }^{4}$ The Holding Company for Biological Products, Vaccines and Drugs (VACSERA), Dokky, Giza, Egypt.
}

*Corresponding author: mahmoud_tawfick@azhar.edu.eg

doi: 10.15414/jmbfs.2016/17.6.3.937-942

\section{ARTICLE INFO}

Received 18. 8. 2016

Revised 7. 10. 2016

Accepted 20. 10. 2016

Published 1. 12. 2016

Regular article OPEN $\partial_{\text {ACCESS }}$

\begin{abstract}
Hepatitis A virus (HAV) is one of the most common causes of acute viral hepatitis worldwide. Formaldehyde is the currently used inactivating agent in HAV vaccine processing despite of its adverse effects. The current study aimed to evaluate both L-amino acid oxidase (LAO) and L-ascorbic acid (LAA) as alternative inactivants for HAV and the immunogenicity of inactivated HAV in mice. Vero cell line was used for cultivation of HAV. The cytotoxicity of LAO and LAA on Vero cells was evaluated using 3-(4,5dimethylthiazol-2-yl) 2,5 diphenyl tetrazolium bromide (MTT) assay. The immunogenicity of each LAO- and LAA-inactivated HAV was examined in parallel with reference HAV vaccine in mice. Humoral (total $\operatorname{IgG}$ ) and cellular immune responses (IFN- $\gamma$ and IL-5) were evaluated in mice sera using ELISA. Both LAO and LAA could efficiently inactivate HAV within 30 and 36 hrs post treatment, respectively, at concentrations of $0.4 \mu \mathrm{gm} / \mathrm{ml}$ of LAO and $1.5 \mathrm{mg} / \mathrm{ml}$ of LAA. Inactivated vaccines were immunogenic to mice on both the humoral and cellular levels. LAO prepared vaccines showed a more promising immune reactivity than LAA prepared ones and alum-adsorbed vaccines were more immunogenic than non-adjuvanted ones. In conclusion, data recorded suggest that both LAO and LAA can be used as inactivating agents for HAV grown in cell culture. LAA- and LAO-inactivated HAV can be potential vaccines as they provide effective humoral and cellular immune responses comparable to that of the reference vaccine. The stability of test vaccines is recommended to be traced at different thermal conditions, in addition to different stabilizers and different pharmaceutical formulations must be tested trying to produce a lyophilized formula for long-term stability.
\end{abstract}

Keywords: Hepatitis A, vaccine, virus inactivation, L-amino oxidase, L-ascorbic acid, alum

\section{INTRODUCTION}

Hepatitis A virus (HAV) is the most common cause of infectious viral hepatitis which is acquired via the faecal-oral route. Hepatitis $\mathrm{A}$ is a common infection worldwide that is associated with unsafe drinking water, inadequate sanitation and poor personal hygiene (Wu and Guo, 2013). It is estimated that approximately 1.5 million clinical cases of HAV infection occur worldwide per annum. In addition, HAV infection is very common in underdeveloped countries such as Africa, parts of South America, the Middle East and India. In high endemic areas, hepatitis A occurs early in childhood; however, the development in sanitary conditions has resulted in a shift of the age groups affected by hepatitis A with increasing incidence in older age groups (Sartori et al., 2012). In Egypt, a study that has been performed in 2008 revealed that the frequency of HAV infection in children from low social class was high $(81 \%)$, while the prevalence rate was low $(27.3 \%)$ in those of higher classes (Franco et al., 2012). The disease is self-limited however HAV infection may result in acute liver failure and death, while risk increases with age and the presence of chronic liver disease (Wu and Guo, 2013). Prevention of HAV infection could be achieved by avoidance of exposure to contaminated food and water, proper disposal of excreta as well as administration of vaccine to those risk groups, such as health care workers (Zuckerman et al., 2009). Indeed, universal immunization would successfully control hepatitis A, although high costs and limited availability of vaccines preclude such a recommendation (Tahaei et al., 2012).

Vaccines against viral infections consist mostly of live attenuated or inactivated viruses (Stauffer $\boldsymbol{e t} \boldsymbol{a l}$., 2006). In 1992, two HAV formalin-inactivated vaccines, namely Havrix (GSK) and VAQTA (Merck), were available in United States and some other developed countries. These vaccines were developed by growing the virus in human diploid cell lines and then inactivated by treatment with formaldehyde (Karayiannis et al., 2004). Other formalin-inactivated HAV vaccines include Avaxim (Sanofi Pasteur) and Epaxal (Crucell Switzerland)
(Glück et al., 1992; Vidor et al., 1996). These vaccines are administered intramuscularly as a two-dose regimen, given at zero and six to 12 months. They generally well tolerated, with occasional reports of mild local reactions or, more rarely, fever and malaise (Karayiannis et al., 2004; Tahaei et al., 2012). Immunity induced by these vaccines is achieved in approximately $100 \%$ of immunocompetent patients one month after receiving the recommended two doses (Fiore et al., 2006).

Several inactivating agents have been described to successfully inactivate viruses for vaccine purposes. Still, formaldehyde is the most widely used inactivating agent in vaccine industry for decades (Madhusudana et al. 2004). However, formaldehyde inactivation efficacy varies between vaccines concerning formalin concentration, time of inactivation and temperature. Generally, the higher the formalin concentration and temperature the faster is the inactivation, although this may adversely affect the antigenicity owing to thermal degradation and destruction of important epitopes (Sanders $\boldsymbol{e t}$ al., 2015). As the integrity of the immunological epitopes of inactivated vaccines is virus-inactivant related. Therefore, it is a matter of interest to evaluate cheap and easily available alternative chemicals for fast and efficient inactivation of viruses without affecting its antigenicity (Madhusudana et al., 2004). Some studies have revealed that L-ascorbic acid (LAA) or vitamin C can be used as an inactivating agent for both DNA and RNA viruses while retained good antigenicity (White et al., 1986; Rawal et al., 1995; Madhusudana et al., 2004; Abd El-Razek et al., 2011). In addition, several studies reported that Lamino acid oxidas (LAO) present in animal secretary fluids, scorpion and snake venoms have strong antimicrobial activities against various pathogenic bacteria and viruses (Meenakshisundaram et al., 2009; Alyan et al., 2014; Kasai et al., 2015). Izidoro (2014) reported the possible inhibition of HIV-1 replication by LAO isolated from Trimeresurus stejnegeri venom. Based on the available information on virus inactivation efficacy of both LAO and LAA, the objective 
of our study was to evaluate them as alternative inactivants to HAV and related immunogenic efficacy of both LAO- and LAA-inactivated HAV in mice.

\section{MATERIAL AND METHODS}

\section{Hepatitis A virus strain and cell line}

HAV strain HM175 was kindly supplied from water pollution department, National Research Centre, Cairo, Egypt. African green monkey kidney cell line [Vero cells, clone CCL-81] was kindly provided by Research and Development Sector, the Egyptian Holding Company for Biological Product and Vaccines (VACSERA, Giza, Egypt).

\section{Maintenance of Vero cell line}

The 199 Eagle [E-199] medium (GIBCO, USA) supplemented with $200 \mathrm{mM} \mathrm{L}$ glutamine, $10 \%$ foetal calf serum (FCS) (Sigma Aldrich, USA), $100 \mathrm{IU} / \mathrm{ml}$ of penicillin and $100 \mathrm{mg} / \mathrm{ml}$ of streptomycin (Invitrogen, USA) was used to maintain Vero cell line in tissue culture flasks (TPP, Switzerland) according to Doyle and Bryan (1998) and Mather and Roberts (1998), where the growth medium of the mother bottle was decanted. It was incubated at $37^{\circ} \mathrm{C}$ in $5 \% \mathrm{CO}_{2}$ incubator (Jouan, France) until monolayer was developed. The monolayer was washed gently using sterile phosphate buffered saline [PBS] of $\mathrm{pH}$ 7.2. PBS was decanted and the cell monolayer was washed with $10 \mathrm{ml}$ pre-warmed $0.25 \%$ (W/V) trypsin-EDTA solution [Invetrogen, USA] and left in contact with cells for 15 - 30 seconds. Trypsin was decanted, the TC flasks were incubated with the trace trypsin at $37^{\circ} \mathrm{C}$ until the cells detach from the surface. Cells were dispensed in number of flasks to maintain cell count of $\sim 2 \times 10^{5} / \mathrm{ml}$. TC flasks were kept till monolayers were developed. The actual cell number in the suspension was calculated by counting the cells using the haemocytometer and trypan blue dye (Sigma Aldrich, USA) exclusion method.

\section{Virus seed stock preparation.}

Maintained Vero cells were inoculated with the HAV. The growth medium was carefully decanted and HAV as 0.1 MOI (multiplicity of infection) was inoculated onto Vero cells. HAV infected flasks were shaken for 15 minutes intervals to assure well virus distribution. Maintenance medium $(100 \mathrm{ml})$ was then added to each infected flask. Infected flasks were incubated at $37^{\circ} \mathrm{C}$ and examined microscopically every day till the development of cytopathic effect (CPE). Flasks developed CPE were subjected to freezing and thawing three times to extract both cell free and cell associated virus from cells (ELKaramany, 1987).

\section{HAV seed stock infectivity titration}

HAV harvest was titrated on Vero cells, where HAV seed was 10-fold serially diluted using sterile E-199 medium. Dilutions of HAV were dispensed to Vero cells pre-cultured 96 -well plates as $0.1 \mathrm{ml} /$ well. Plates were incubated at $37^{\circ} \mathrm{C}$ for 7 days with daily microscopic examination using inverted microscope (Hund, Germany). Infectivity titre was determined according to Reed and Muench (1938) equation:

PD Index $=(\mathrm{A}-50 \%) /(\mathrm{A}-\mathrm{B}) \times \log$ dilution $(10)$

Where $\mathrm{A}$ is the percentage of CPE at dilution immediately above $50 \%$ and $\mathrm{B}$ is the percentage of $\mathrm{CPE}$ at dilution immediately below $50 \%$. After that index was applied to the dilution that produced the percentage of cytopathic effects immediately above $50 \%$.

\section{Chemical inactivants}

L-amino oxidase (LAO) and L-ascorbic acid (LAA), used for HAV inactivation in this study, were purchased from Sigma Aldrich, USA. They were prepared at a concentration of $1 \mathrm{mg} / \mathrm{ml}$ and processed for evaluation of their safe concentrations. LAA solution contained $\mathrm{CuSO}_{4}$ at a final concentration of 5 $\mu \mathrm{g} / \mathrm{ml}$.

\section{MTT assay}

Cytotoxic effects of both LAO and LAA was determined on Vero cells using 3 (4,5-dimethylthiazol-2-yl) 2,5 diphenyl tetrazolium bromide (MTT), where Vero cells were dispensed in 96 well plates. Plates were incubated till confluency. Test inactivants were 2 -fold serially diluted and $24 \mathrm{hrs}$ post incubation at $37^{\circ} \mathrm{C}$, dead cells were washed out using PBS. Remaining viable cells were stained with MTT stain as $50 \mu \mathrm{l}(5 \mathrm{mg} / \mathrm{ml}) /$ well. Plates were incubated at $37^{\circ} \mathrm{C}$ for $3-4 \mathrm{hrs}$. Developed crystals were dissolved using $0.4 \%$ acidified iso-propanol or Dimethyl sulphoxid (DMSO). Developed colour was read at $570 \mathrm{~nm}$ wave length using Biotek- ELx-800 ELISA microtiter plate reader. The viable cell number was calculated according the equation: Viable $\%=$ OD Test $\times 100 /$ OD of cont The safe concentration of test inactivant was determined.

\section{Determination of inactivation kinetics of HAV}

Inactivation kinetic relative to time post treatment with LAO and LAA was determined according to Madhusudana (2004) and El-Karamany (1987) where $1 \mathrm{ml}$ of chemically treated virus was collected at time interval of one hour. Virus samples were 10 -fold serially diluted $10^{1}-10^{8}$ in 199-E medium. Prepared dilutions were dispensed onto 24 hrs pre-cultured Vero cells in 96 well plates (TPP-Swiss). Infected plates were kept at $37^{\circ} \mathrm{C}$ in $5 \% \mathrm{CO}_{2}$ (Jouan-France) with daily microscopic observation using inverted microscope for detection of the CPE. The $50 \%$ end point induced CPE was determined according to Reed and Muench (1938)

\section{Acute toxicity of test inactivants}

Acute toxicity of each test inactivants was performed according to Abd ElRazek et al. (2011). Intraperitoneal acute toxicity was studied in Swiss Webster male mice. The animals had free access to feed and drinking water. Mice were allocated into groups (10/cage). Test chemicals safe concentrations were administered intraperitonealy. General symptoms of toxicity and mortality were observed for 24 hrs, after which the animals were left for further 7 days for delayed toxicity.

\section{Aluminum phosphate (Alum) adjuvant}

The solutions of each of $0.63 \mathrm{M} \mathrm{AlCl}_{3} .6 \mathrm{H}_{2} \mathrm{O}$ and $0.3 \mathrm{M} \mathrm{Na}_{3} \mathrm{PO}_{4} .12 \mathrm{H}_{2} \mathrm{O}$ were prepared in $40 \mathrm{ml}$ normal saline. Prepared solutions were $0.2 \mu \mathrm{m}$ filtered. Contents were stirred continuously during the procedure at 40 to $60 \mathrm{rpm}$. After wards, $0.3 \mathrm{M} \mathrm{Na}_{3} \mathrm{PO}_{4} .12 \mathrm{H}_{2} \mathrm{O}$ solution was added to the mixing bottle, and then $300 \mathrm{ml}$ normal saline was added. The antigen was also added followed by addition of $0.63 \mathrm{M} \mathrm{AlCl}_{3} .6 \mathrm{H}_{2} \mathrm{O}$ solution to the mixing bottle. The $\mathrm{pH}$ was maintained between $6.5-6.8$. The final volume was adjusted with sterile normal saline and the suspension was mixed for $2 \mathrm{hrs}$ at $37^{\circ} \mathrm{C}$ (Gupta, 1998; Lindblad, 2004).

\section{Mice immunization}

Six to eight weeks old Swiss Webster male mice, housed at the animal facility of VACSERA, Giza, Egypt, were used in this study according to the recommendations of Animal Care and Use Committee (ACUC). Alum was used as adjuvant at concentration of $0.35 \mathrm{mg} / \mathrm{ml}$ to enhance the immune response to the injected inactivated virus. In this study, five groups of mice, 10 each, were immunized subcutaneously. Four groups were immunised individually with LAO- and LAA-inactivated HAV, alum adsorbed and none-adsorbed, while the fifth group was immunised with the currently marketed HAV vaccine Havrix Havrix is an alum-adsorbed commercial vaccine (Glaxo SmithKline) containing 1440 ELISA units [EU] of formalin-inactivated HAV as a positive control. Immunized mice were bled through retro orbital plexus. Immune sera prepared from blood samples collected from each group at a two-week interval postimmunization. Antibody level [IgG] and cytokines [IFN- $\gamma$ and IL-5] produced post-immunization were monitored.

\section{Detection of HAV-specific antibodies in mice sera}

Antibodies against HAV vaccine were detected in post-immunization sera samples using enzyme-linked immunosorbent assay (ELISA) according to Abd El-Razek et al. (2011), where sera samples were diluted as 1/100 in dilution buffer (PBS + $1 \%$ BSA) and added to HAV antigen pre-coated 96-well maxisorb ELISA plates. Sera samples were serially diluted and plates were incubated for an hour at $37^{\circ} \mathrm{C}$. Plates were washed three times with $300 \mu \mathrm{l}$ of $1 \times$ wash buffer (PBS $+0.05 \%$ Tween 20) using automated ELISA plate washer for better washing performance. Then, $100 \mu \mathrm{l}$ of anti-mouse IgG-HRP conjugate were added to all wells leaving one empty for the substrate blank. Plates were mixed gently for 5-10 seconds and then incubated for 60 minutes at $37^{\circ} \mathrm{C}$. Plates were washed as previous. Tri Methyl Benzdeine (TMB) substrate buffer (Sigma Aldrich, USA) was added as $100 \mu \mathrm{l} /$ well and plates were kept in dark for 20 minutes at room temp. The reaction was stopped using $100 \mu \mathrm{l}$ of $2 \mathrm{~N} \mathrm{H}_{2} \mathrm{SO}_{4}$ Optical density of developed colour was measured at $450 \mathrm{~nm}$ using BioTek-XL800 -USA) ELISA reader within $60 \mathrm{~min}$.

\section{Cytokines determination}

The amounts of IFN- $\gamma$ and IL-5 in mice immune sera were assayed using specific sandwich ELISA kit for each cytokine (eBiosciences, USA) according to the manufacturers' instructions.

\section{Statistical analysis}

Results are expressed as mean values for three three independent experiments Comparison between the different groups was made using unpaired student $t$ - 
tests to assess significance using GraphPad Prism 5 software. Differences at $P$ values less than 0.05 were considered significant.

\section{RESULTS AND DISCUSSION}

\section{Treatment with LAA or LAO could successfuly inactivate HAV}

Testing the cytotoxic effects of test inactivants LAO and LAA showed that the safe concentrations were $0.4 \mu \mathrm{g} / \mathrm{ml}$ and $1.5 \mathrm{mg} / \mathrm{ml}$, respectively. These concentrations were used to inactivate HAV, which showed no toxicity to mice as all inoculated tmice were alive throughout the designed 7-day period of test. Data recorded revealed that HAV was completely inactivated within $30 \mathrm{hrs}$ and $36 \mathrm{hrs}$ post-treatment with LAO and LAA, respectively, and no residual infective virus was detected (Figure 1).

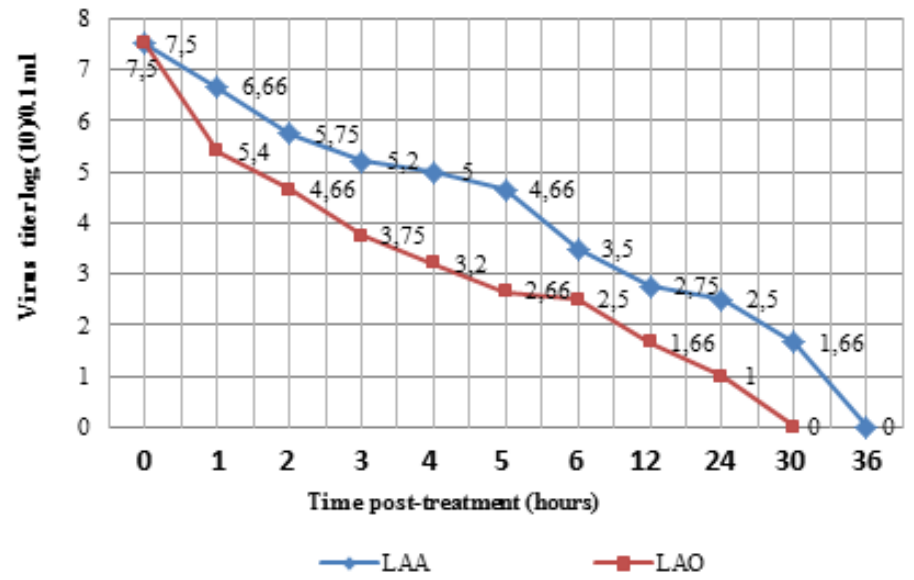

Figure 1 Evaluation of inactivation kinetics of HAV post-treatment with each LAO and LAA relative to time using cell culture assay.

Each of LAA- and LAO-inactivated HAV induced humoral and cellular immune responses in mice

Regarding the humoral immune response, total HAV-specific IgG response was monitored. Data recorded revealed that HAV-specific IgG antibodies were detectable in the mice immune sera as early as two weeks and the peak was detected at the $6^{\text {th }}$ week and $8^{\text {th }}$ week post-immunization with test LAOinactivated vaccines either alum adjuvanted or non-adjuvanted and LAAinactivated vaccines either alum adjuvanted or non-adjuvanted, respectively. There was a significant difference $(P<0.05)$ in the level of the antibody production, which was detected 14 weeks post-immunisation with LAO prepared vaccine than those detected post-immunization with LAA prepared vaccines. Alum adjuvanted vaccines showed a significant elevated antibody level $(P<$ $0.05)$ than non-adjuvanted ones throughout the immunization course. Based on the antigen content, the purchased reference vaccine showed the highest level of antibody response (Figures 2, 3).
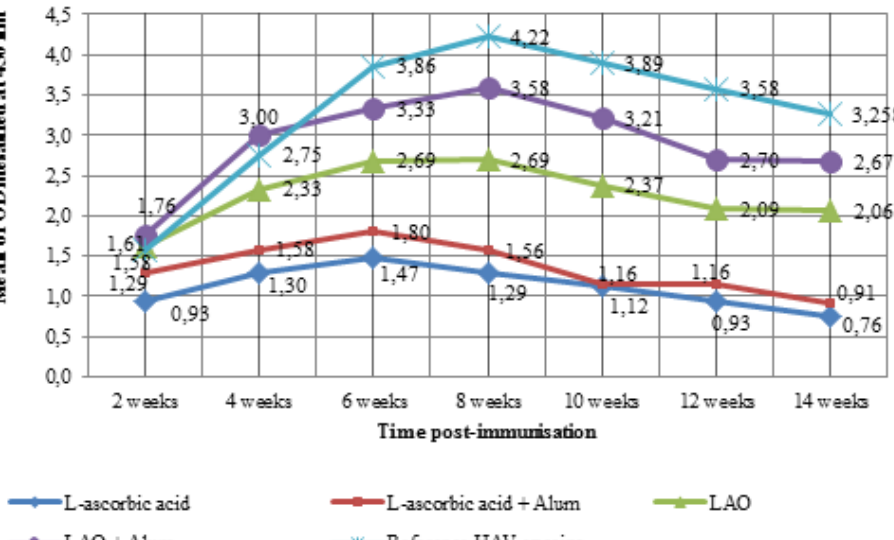

$-\mathrm{LAO}+\mathrm{Alum}$

-Reference HAV vacin

Figure $2 \mathrm{IgG}$ immune response of mice immunised with alum adjuvanted and non-adjuvanted LAA- and LAO-inactivated HAV vaccines, relative to time postimmunisation
Fourteen weeks post-immunisation

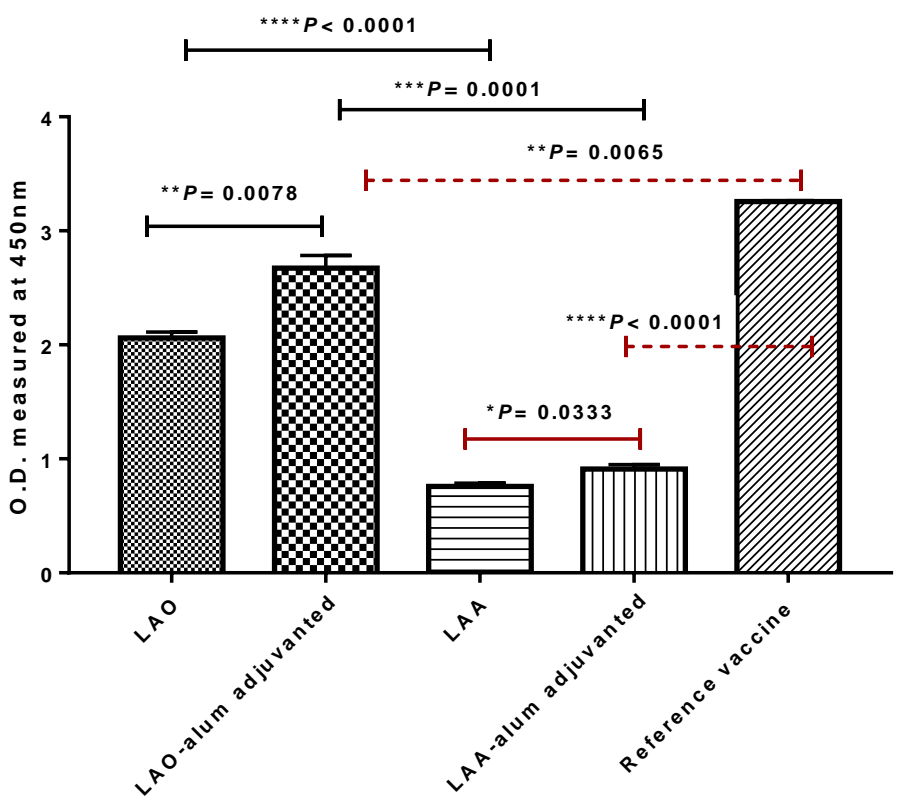

HAV vaccine candidate

Figure $3 \mathrm{IgG}$ immune response in mice 14 weeks post-immunization with HAV vaccines. Data presented as mean $\pm \mathrm{SE}$ of three replicates.

Concerning the cellular immune response, IFN- $\gamma$ and IL-5 cytokines were estimated in immunised mice sera. The production of these cytokines could be detected as early as 3 days post-immunisation with HAV-inactivated vaccines The level of IFN- $\gamma$ was significantly higher $(P<0.05)$ in case of both alum adjuvanted LAA- and LAO-inactivated HAV vaccines than non-adjuvanted ones until 28 days pos-immunisation. The alum adjuvanted LAO- and LAAinactivated vaccines showed high levels than that produced by purchased positive control vaccine $(P<0.05)$ at 14 days and 21 days post-immunisation. At 28 days post-immunisation, there was no significant difference $(P<0.05)$ between the level produced by LAO-adjuvanted vaccine and that of the purchased vaccine $(P$ $>0.05$ ), while that of LAA-adjuvanted vaccine was slightly higher at $P<0.05$ indicated by one asterisk. LAO-inactivated vaccines produced significantly higher levels of IFN- $\gamma(P<0.05)$ than that produced by LAA-inactivated ones at 14,21 and 28 days post-immunisation denoted by four asterisks, except at 28 days, there was no significant difference $(P<0.05)$ between adjuvanted ones (Figures 4, 6)

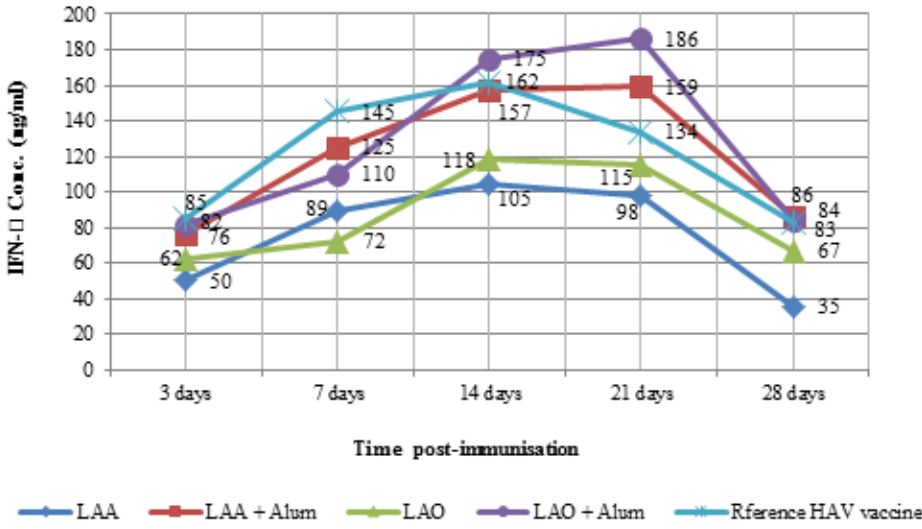

Figure 4 Estimation of IFN- $\gamma$ concentration in mice sera post-immunisation with LAO- and LAA-inactivated HAV vaccines using specific sandwich ELISA

IL-5 level was significantly higher $(P<0.05)$ in both LAO- and LAA-inactivated vaccines adjuvanted with alum than those non-adjuvanted ones at 14, 21 and 28 days post-immunisation. LAO-inactivated vaccines produced significantly higher levels of IL-5 $(P<0.05)$ than that produced by LAA-inactivated ones. The IL-5 level produced by purchased vaccine was significantly higher $(P<0.05)$ than that produced by test vaccines at 14,21 and 28 days post-immunization except LAOadjuvanted one which was significantly higher $(P<0.05)$ than control vaccine at 21 days (Figures 5, 6). 


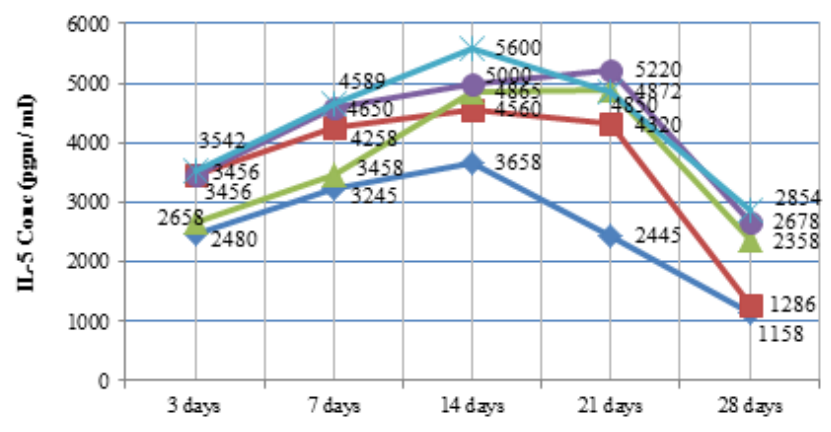

Time post-immurization

$\longrightarrow$ LAA $\rightarrow$ LAA + Alum $\longrightarrow$ LAO $\leadsto$ LAO + Alum $\because$ Rference HAV vaccine

Figure 5 Estimation of IL-5 concentration in mice sera post-immunization with LAO- and LAA-inactivated HAV vaccines using specific sandwich ELISA.
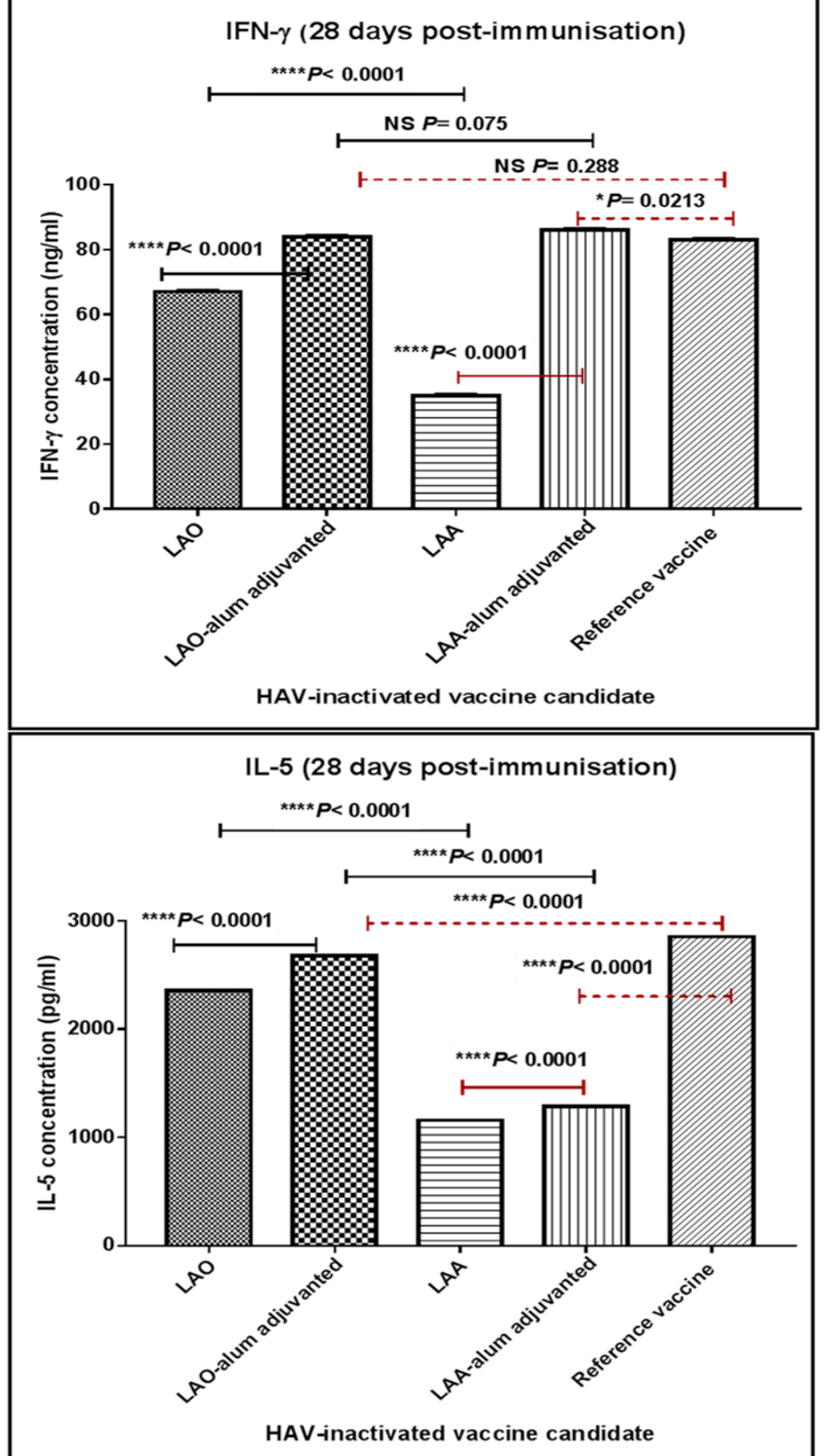

Figure 6 IFN- $\gamma$ and IL-5 concentrations in mice sera at 28 days postimmunization with LAO- and LAA-inactivated vaccines.

In the past two decades, the HAV cases have declined in several parts of the world due to partly the developed vaccines (Kanyenda et al., 2015). The commercially available HAV vaccines contain formalin-inactivated HAV, grown on human cell lines and purified, that has been adsorbed with alum to enhance its immunogenicity. While they are considered efficacious, often multiple boosters are required to confer protection against HAV. These vaccines are also very expensive to produce, available in limited quantities, and must be kept cold until they are administered by injection (Mitchell and Galun, 2003). Still in developing countries, such as Egypt, HAV vaccination may be considered on the basis of epidemiological and cost-effectiveness concerns. Thus, the available HAV vaccines are not yet commonly used (Franco et al., 2012). Viral inactivation is an important procedure in vaccine development against viral infections (Stauffer et al., 2007). However, the inactivating agent may have an effect on the viral epitopes pattern to which the antigenicity and/or immunogenicity of vaccine is related (Blackburn and Besselaar, 1991). Thus, the inactivation procedures may drastically impair induction of neutralizing $\mathrm{IgG}$ antibodies responses for most viruses (Bachman et al., 1994). Formaldehyde is the inactivating agent used for HAV vaccines (Chowdhury et al., 2015) However, it was observed that for formalin inactivation concentration, $\mathrm{pH}$ temperature and medium composition are extremely critical factors. Formalin was found to require at least $24-96 \mathrm{hrs}$ at $4^{\circ} \mathrm{C}-37^{\circ} \mathrm{C}$ for inactivation. In addition, the higher concentrations of formaldehyde and temperature used to speed up the inactivation may harmfully affect the immunogenicity of inactivated virus (Chowdhury et al., 2015; Sanders et al., 2015). Seriously, an incomplete formaldehyde inactivation procedure may be fatal for public health. For example, incomplete inactivation of the Venezuelan equine encephalitis vaccines, prepared by formalin inactivation, was the cause of the outbreak of the disease during the 1969 - 1972 pandemic in Central America (Brown, 1992). Furthermore, formaldehyde which is an alkylating agent inactivates viruses via chemical reaction with viral capsid proteins and nucleic acid (Budowsky et al., 1991), and it has been classified by International Agency for Research in Cancer (IARC) under group 2A. However, there is no epidemiological data referring to the carcinogenic risk of the alkylating agents on humans (Chowdhury et al., 2015) Owing to previous data, there is a need for available, cheap and efficient alternatives for fast inactivation of HAV without affecting its immunogenicity allowing HAV vaccines to be less expensive to be manufactured and more amenable to mass vaccination programs. Thus, the main objective of the present study was to evaluate the efficiency of LAO and LAA as inactivants of HAV and examine the immunogenicity of each LAA- and LAO-inactivated HAV compared with the currently available formaldehyde prepared vaccine.

In the present study, both test inactivants could successfully inactivate HAV using safe concentrations $(0.4 \mu \mathrm{gm} / \mathrm{ml}$ of LAO and $1.5 \mathrm{mg} / \mathrm{ml}$ of LAA), within 30 hours and 36 hours post-treatment, respectively. LAO has previously showed remarkable virucidal activities to viruses such as varicella-zoster virus and herpes simplex virus type 2 (Zedan et al., 2003; Alyan et al., 2014). In addition, data recorded of HAV inactivation by LAO in this study is consistent with results of Aly Mohamed and his colleagues (unpublished data), despite the use of another virus model namely Rift Valley fever virus that was completely inactivated with LAO within $6 \mathrm{hrs}$, and the immune potential of this vaccine was better than that of the known $\beta$-propiolactone (BPL)-inactivated vaccine. Recently, snake venom LAO has been recognized as a multifunctional protein with promising biomedica applications because of its antimicrobial, anti-HIV, anticoagulant, and inducing of platelet aggregation. LAO enzyme is acting specifically on L-amino acids and generally on hydrophobic amino acids (Du et al., 2002). The inactivation of HAV by LAO is possibly due to the oxidizing stress of LAO attributed to the ability of the enzyme to localize $\mathrm{H}_{2} \mathrm{O}_{2}$ to the target cells through channels in its structure that would direct the $\mathrm{H}_{2} \mathrm{O}_{2}$ product to the exterior surface of the protein near the glycan moiety. Thus, the glycan moiety is thought to be involved with LAO-target cell interaction. Accordingly, the virucidal activity of LAO was the base on which it was used as virucidal agent to prepare an improved HAV vaccine (Shebl et al., 2012).

Regarding the cytotoxicity of LAO, our findings were found to be in agreement with Shebl et al. (2012) study which revealed that LAO showed significant cytotoxicty to Vero normal cells at concentrations higher than $0.4 \mu \mathrm{gm} / \mathrm{ml}$. The LAO cytotoxicity may be attributed to the released $\mathrm{H}_{2} \mathrm{O}_{2}$ enhancing the oxidative stress on cell nucleus causing cell death and progressive apoptosis. Concerning the use of LAA as an inactivant for HAV, our findings are supported by Madhusudana et al. (2004) that ascorbic acid can be used as an inactivating agent for viruses grown in cell line although the authors used it for rabies virus. In addition, earlier experiments used LAA as an inactivating agent for both RNA and DNA viruses, confirmed its efficiency as inactivating agent for number of viruses including vaccinia virus (Turner et al., 1964) HIV virus (Rawal et al., 1995) and in vitro infectivity of herpes viruses and paramyxoviruses (White $\boldsymbol{e t}$ al., 1986). Abd El-Razek et al. (2011) study revealed also the complete effective inactivation of Rift Valley fever virus using LAA for vaccine development. The mechanism whereby ascorbic acid inactivates viruses is not fully understood Although, it was partly explained by the presence of oxygen which is essential and ascorbic acid undergoing auto-oxidation results in the formation of $\mathrm{OH}$ groups that could bring about the inactivation of the cell free viruses (Murata $e t$ al., 1986).

The mice immunisation experiments performed in this study revealed that both inavtivated HAV vaccines induced a good antibody (humoral) immune response as indicated by the results of the HAV-specific IgG ELISA. Regarding the immunogenicity of LAO-inactivated vaccine, the results revealed that HAVspecific antibodies were detected 14 days post-immunization and this was in agreement with Keeffe $\boldsymbol{e t}$ al. (1989), despite their trial was conducted on the 
clinical level. Whilst, the immune response peak was on the $8^{\text {th }}$ week postimmunization with LAO or LAO alum adjuvanted vaccine, similar to the antibody response produced by HAV reference vaccine, and on the $6^{\text {th }}$ week postimmunization for LAA or LAA alum adjuvanted vaccine. Subsequently, the level of antibody production starts to decrease. Natural infection with Hepatitis A virus leads to life long detectable antibody in most individuals, whereas vaccine induced antibody levels wane over time. In healthy adults, vaccine induced antiHAV has been observed to decrease rapidly from one month after the booster vaccination until six month later, followed by a rather constant decrease over the subsequent two years, approximately $14 \%$ per year (Van Damme $\boldsymbol{e t}$ al., 1994). Thus, in most countries, booster-vaccination policy is guided by manufacturers recommendations, national authorities, or both. Data showed that after a full primary vaccination course, protective antibody amounts persist beyond 10 years in healthy individuals, and underlying immune memory provides protection far beyond the duration of anti-HAV antibodies (Van Damme et al., 2003).

One of the major cellular effectors is the CD4+ helper T cells that elaborate cytokines which enhance both antibody and cellular immune responses. For investigating the cellular immune response in immunised mice and the predominant phenotype, cell-mediated (Th1) or humoral (Th2) immune responses elicited by immunization with LAO- or LAA-inactivated HAV, the level of two cytokines IFN- $\gamma$ (Th1 cytokine) and IL-5 (Th2 cytokine) were estimated in the post-immunisation sera. The cytokine-specific sandwich ELISA results revealed that the mice immune response generated with both LAA- and LAO-inactivated HAV immunisation was a mixed Th1/Th2 immune response profile similar to that produced by HAV reference vaccine. However, the quantitative measurement of the level of each cytokine indicated that the concentrations of Th1 cytokine IFN- $\gamma$ (cellular immunity) was higher than that of Th2 cytokine IL-5 (humoral immunity). These results indicated that the extent of up-regulation of IFN- $\gamma$ production was the highest when compared to that of IL5 , confirming a significant Th1 immune response. Accordingly, there was distinct humoral and cellular immune responses post-immunisation with both LAA- and LAO-inactivated HAV. Consistent with our results, Schmidtke et al. (2005) study results which revealed that both distinct $\mathrm{B}$ and $\mathrm{T}$ cell responses were determined within 14 days after immunisation with formalin-inactivated vaccine (Havrix) in humans. However, the cellular immune response in the current study might be the predominant one which is fitting for vaccination against viral infections by HAV. That is because the cellular immune response is very vital for combating viral infections (Lappin and Campbell, 2000). In addition, clinica and experimental evidence proved the hypothesis that HAV hepatocellular damage and the efficient elimination of virus-infected hepatocytes are mediated by virus-specific, proliferating T lymphocytes derived interferon (Schmidtke $\boldsymbol{e}$ al., 2005). The data recorded in this study concerning type of immune responses was also in agreement with Cederna et al. (1999), despite their trial was on the clinical level, which revealed that HAV antibody and proliferative effective $\mathrm{T}$ cell response were elicited by a formalin-inactivated HAV vaccine in the immunized subjects. However, antibodies produced against HAV are present over an extended period in the human sera, indicating the likely importance in maintaining providing a long-term immunity (Wang et al., 1996). These result indicated the high and good immunogenicity of each of LAA- and LAOinactivated HAV in Swiss Webster mouse strain. Although, there was no significant difference in the immunogenic potential between the LAO- and LAAinactivated $\mathrm{HAV}$; both showed equivalent antigenic potency as measured by indirect ELISA.

The concentrations of Th1 cytokine IFN- $\gamma$ in alum adsorbed LAA- and LAOinactivated HAV was higher in those non-adsorbed ones. This finding is consistent with the practically established concept that alum adjuvant is administered with antigens in experimental murine and rabbit immunization studies to enhance immunity (Gupta, 1998; Lindblad, 2004). Indeed, all HAV commercially available formalin-inactivated vaccines are adsorbed onto alum as an adjuvant (Karayiannis et al., 2004; Tahaei et al., 2012). Previous published studies concerned the cellular immune response to vaccine prepared using LAO as a natural product is very rare as the majority of inactivating agents are chemicals in nature not natural derivatives. However, the use of LAA as an inactivating agent showed similar immune response, and particularly the cellular immune response pattern as in case of inactivation of rabies virus reported by Madhusudana et al. (2004) and Abd El-Razek et al. (2011). Thus, it was hardly to compare HAV vaccine potentials to other prepared vaccines using another inactivating agent but using the same technique except in case of preparing Rift Valley fever virus vaccine inactivated with both BPL and LAO despite the previous reporting of LAO as a virucidal agent to Rift Valley fever Virus, Vesicular Stomatitis Virus (VSV), Herpes and Adeno viruses (Abd El-Razek $\boldsymbol{e}$ al., 2011; Alyan et al., 2016). Accordingly, data recorded regarding the immune response is in agreement with one of the authors of this study, Aly Mohamed and his colleagues (unpublished data), that LAO-inactivated Rift Valley fever vaccine was high immunogenic than the BPL-inactivated one. The use of alumadjuvanted vaccines has showed a better immune response than non-adjuvanted ones.

\section{CONCLUSION}

It can be reported that both LAA and LAO are promising and equally efficient for inactivation of HAV. Each of LAA- and LAO-inactivated HAV appears to provide potentially effective anti-HAV vaccines owing to the finding that they induced both good humoral and cellular immune responses. The immune potentials of both LAA- and LAO-inactivated vaccines are almost equally to that of formalin-inactivated HAV vaccines currently available in the Egyptian market. There was no distinguished difference in the values of cellular immune response parameter of interest. Both HAV-inactivated vaccines were biologically of near bio-reactivity to immune system. Alum as adjuvant is useful to enhance the immune potentials of inactivated HAV on the experimental level. However, the present study is limited by showing the immune response only for days and/or weeks, thus long-term tracing of immune response on both the cellular and humoral levels is warranted. The HAV-inactivated vaccines in the current study were not challenged in experimental animals as human is the only reservoir host of HAV and the lack of animal model that mimics the human infection. An extensive investigation of the HAV vaccine-induced immune response should include the analysis of circulating HAV-specific T lymphocytes. As storage, handling and the heat stability of vaccines are consequently matters of great concern. Thus, studying the stability either real time or accelerated one and tracing the accumulative effect of residual LAO is recommended on the biochemical pathological level. Both LAO and LAA should be further compared with other inactivating agents along with testing different inactivation agents and/or vaccine adjuvants to maximize the immune response and formulate the best suitable method for HAV vaccine preparation.

\section{REFERENCES}

Abd El-Razek, N. E. E.-D, Shoman, S. A., \& Mohamed, A. F. (2011) Nanocapsulated Rift Valley Fever vaccine candidates and relative immunological and histopathological reactivity in out bred Swiss mice. Journal of Vaccines \& Vaccination, 02(01). http://dx.doi.org/10.4172/2157-7560.1000115

Alyan, M. S., Shalaby, M. A., El-Sanousi, A. A., Fahmy, A., El-Sayed, M., \& Shebl, R. I. (2014). Antiviral and Anticancer Potentials of Snake and ScorpionVenom Derivatives. Inventi Rapid: Molecular Pharmacology, 2014(2), $1-11$.

Alyan, M., Shalaby, M., El-Sanousi, A., El-Sayed, A., \& Shebl, R. (2016). New Trends in Cancer Therapy and Antiviral Drug Research. International Journal of Advanced Research, 4(5), 698-710. http://dx.doi.org/10.21474/ijar01/408

Bachmann, M. F., Bast, C., Hengartner, H., \& Zinkernagel, R. M. (1994). Immunogenicity of a viral model vaccine after different inactivation procedures. Medical microbiology and immunology, 183(2), 95-104 http://dx.doi.org/10.1007/bf00277160

Blackburn, N. K., \& Besselaar, T. G. (1991). A study of the effect of chemical inactivants on the epitopes of Rift Valley fever virus glycoproteins using monoclonal antibodies. Journal of virological methods,33(3), 367-374. http://dx.doi.org/10.1016/0166-0934(91)90036-y

Brown, F. (1992). Review of accidents caused by incomplete inactivation of viruses. Developments in biological standardization, 81, 103-107.

Budowsky, E. I., Friedman, E. A., \& Zheleznova, N. V. (1991). Principles of selective inactivation of viral genome. VII. Some peculiarities in determination of viral suspension infectivity during inactivation by chemical agents. Vaccine, 9(7), 473-476. http://dx.doi.org/10.1016/0264-410x(91)90031-z

Cederna, J. B., Klinzman, D., \& Stapleton, J. T. (1999). Hepatitis A virusspecific humoral and cellular immune responses following immunization with a formalin-inactivated hepatitis A vaccine. Vaccine, 18(9), 892-898 http://dx.doi.org/10.1016/s0264-410x(99)00342-4

Doyle, A., \& Bryan, G. J. (1998). Cell and tissue culture: laboratory procedure in biotechnology. Chicester: John Willey \& Sons.

Du, X. Y., \& Clemetson, K. J. (2002). Snake venom L-amino acid oxidases.Toxicon, 40(6), 659-665. http://dx.doi.org/10.1016/s0041 0101(02)00157-5

Ecobichon, D. J. (1997). The basis of toxicity testing. CRC press.

El-Karamany, R. M. (1987). Production in Vero cells of an inactivated rabies vaccine from strain FRV/K for animal and human use. Acta virologica, 31(4) 321-328.

Fiore, A. E., Wasley, A., \& Bell, B. P. (2006). Prevention of hepatitis A through active or passive immunization. MMWR. Morbidity and Mortality Weekly Report, 55(RR07), 1-23. http://dx.doi.org/10.1037/e566492006-001

Franco, E., Meleleo, C., Serino, L., Sorbara, D., \& Zaratti, L. (2012). Hepatitis A: epidemiology and prevention in developing countries. World J Hepatol, 4(3), 68 73. http://dx.doi.org/10.4254/wjh.v4.i3.68

Franco, Elisabetta, Cristina Meleleo, Laura Serino, Debora Sorbara, and Laura Zaratti. "Hepatitis A: epidemiology and prevention in developing countries." World J Hepatol 4, no. $3 \quad$ (2012): 68-73. http://dx.doi.org/10.4254/wjh.v4.i3.68

Glück, R., Mischler, R., Brantschen, S., Just, M., Althaus, B., \& Cryz Jr, S. J. (1992). Immunopotentiating reconstituted influenza virus virosome vaccine 
delivery system for immunization against hepatitis A. Journal of Clinical Investigation, 90(6), 2491. http://dx.doi.org/10.1172/jci116141

Gupta, R. K. (1998). Aluminum compounds as vaccine adjuvants. Advanced drug delivery reviews, 32(3), 155-172. http://dx.doi.org/10.1016/s0169 409x(98)00008-8

Harrison, T. J., Dusheiko, G. M., \& Zuckerman, A. J. (n.d.). Hepatitis Viruses Principles and Practice of Clinical Virology, 273-320. http://dx.doi.org/10.1002/9780470741405.ch12

Chowdhury, P., Topno, R., Khan, S. A., \& Mahanta, J. (2015). Comparison of $\beta$ Propiolactone and Formalin Inactivation on Antigenicity and Immune Response of West Nile Virus. Advances in virology, 2015. http://dx.doi.org/10.1155/2015/616898

Izidoro, L. F. M., Sobrinho, J. C., Mendes, M. M., Costa, T. R., Grabner, A. N. Rodrigues, V. M., ... \& Calderon, L. A. (2014). Snake venom L-amino aci oxidases: trends in pharmacology and biochemistry. BioMed research international, 2014, 1-19. http://dx.doi.org/10.1155/2014/196754

Kanyenda, T. J., Abdullahi, L. H., Hussey, G. D., \& Kagina, B. M. (2015)

Epidemiology of hepatitis A virus in Africa among persons aged 1-10 years: a systematic review protocol. Systematic reviews, 4(1), 1 http://dx.doi.org/10.1186/s13643-015-0112-5

Karayiannis, P., Main, J., \& Thomas, H. C. (2004). Hepatitis vaccines. British medical bulletin, 70(1), 29-49. http://dx.doi.org/10.1093/bmb/ldh024

Kasai, K., Ishikawa, T., Nakamura, T., \& Miura, T. (2015). Antibacteria properties of 1-amino acid oxidase: mechanisms of action and perspectives for therapeutic applications. Applied microbiology and biotechnology, 99(19), 78477857. http://dx.doi.org/10.1007/s00253-015-6844-2

Keeffe, E. B., Iwarson, S., McMahon, B. J., Lindsay, K. L., Koff, R. S., Manns, M., ... Krause, D. S. (1998). Safety and immunogenicity of hepatitis A vaccine in patients with chronic liver disease. Hepatology, 27(3), 881-886. http://dx.doi.org/10.1002/hep.510270336

Lappin, M. B., \& Campbell, J. D. M. (2000). The Th1-Th2 classification of cellular immune responses: concepts, current thinking and applications in haematological malignancy. Blood reviews, 14(4), 228-239. http://dx.doi.org/10.1054/blre.2000.0136

Lindblad, E. B. (2004). Aluminium adjuvants in retrospect and prospect. Vaccine, 22(27), 3658-3668. http://dx.doi.org/10.1016/j.vaccine.2004.03.032 Madhusudana, S. N., Shamsundar, R., \& Seetharaman, S. (2004). In vitro inactivation of the rabies virus by ascorbic acid. International journal of infectious diseases, 8(1), 21-25. http://dx.doi.org/10.1016/j.ijid.2003.09.002

Mather, J. P., \& Roberts, P. E. (1998). Introduction to cell and tissue culture: theory and technique. Springer Science \& Business Media.

Meenakshisundaram, R., Sweni, S., \& Thirumalaikolundusubramanian, P. (2009). Hypothesis of snake and insect venoms against Human Immunodeficiency Virus: a review. AIDS research and therapy, 6(1), 25 http://dx.doi.org/10.1186/1742-6405-6-25

Mitchell, L. A., \& Galun, E. (2003). Rectal immunization of mice with hepatitis A vaccine induces stronger systemic and local immune responses than parentera immunization. Vaccine, 21(13), 1527-1538. http://dx.doi.org/10.1016/s0264410x(02)00699-0

Murata, A., Kawaaki, M., Motomatsu, H., \& Kato, F. (1986). Virus-inactivating effect of D-isoascorbic acid. Journal of Nutritional Science and Vitaminology, 32(6), 559-567. http://dx.doi.org/10.3177/jnsv.32.559

Rawal, B. D., Bartolini, F., \& Vyas, G. N. (1995). In vitro inactivation of human immunodeficiency virus by ascorbic acid. Biologicals, 23(1), 75-81. http://dx.doi.org/10.1016/1045-1056(95)90016-0

Rawal, B. D., Bartolini, F., \& Vyas, G. N. (1995). In vitro inactivation of human immunodeficiency virus by ascorbic acid. Biologicals, 23(1), 75-81. http://dx.doi.org/10.1016/1045-1056(95)90016-0

Reed, L. J., \& Muench, H. (1938). A simple method of estimating fifty per cen endpoints. American journal of epidemiology, 27(3), 493-497.

Sanders, B., Koldijk, M., \& Schuitemaker, H. (2015). Inactivated Viral Vaccines In Vaccine Analysis: Strategies, Principles, and Control (pp. 45-80). Springer Berlin Heidelberg. http://dx.doi.org/10.1007/978-3-662-45024-6 2

Sartori, A. M. C., de Soárez, P. C., Novaes, H. M. D., Amaku, M., de Azevedo R. S., Moreira, R. C., ... \& Martelli, C. M. T. (2012). Cost-effectiveness analysis of universal childhood hepatitis A vaccination in Brazil: regional analyses according to the endemic context. Vaccine, 30(52), 7489-7497. http://dx.doi.org/10.1016/j.vaccine.2012.10.056

Shebl, R. I., Mohamed, A. F., Ali, A. E., \& Amin, M. A. (2012). Antimicrobia profile of selected snake venoms and their associated enzymatic activities.British Microbiology Research Journal, 2(4), 251 http://dx.doi.org/10.9734/bmrj/2012/2091

Schmidtke, P., Habermehl, P., Knuf, M., Meyer, C. U., Sänger, R., \& Zepp, F. (2005). Cell mediated and antibody immune response to inactivated hepatitis A vaccine. Vaccine, 23(44),

http://dx.doi.org/10.1016/j.vaccine.2005.06.022

Stauffer, F., De Miranda, J., Schechter, M. C., Queiroz, F. A., Santos, N. O. Alves, A. M., \& Da Poian, A. T. (2007). New chemical method of vira inactivation for vaccine development based on membrane fusion inhibition Vaccine, 25(46), 7885-7892. http://dx.doi.org/10.1016/j.vaccine.2007.09.025
Stauffer, F., De Miranda, J., Schechter, M. C., Queiroz, F. A., Santos, N. O., Alves, A. M., \& Da Poian, A. T. (2007). New chemical method of vira inactivation for vaccine development based on membrane fusion inhibition. Vaccine, 25(46), 7885-7892. http://dx.doi.org/10.1016/j.vaccine.2007.09.025 Tahaei, S. M. E., Mohebbi, S. R., \& Zali, M. R. (2012). Enteric hepatitis viruses. Gastroenterology and Hepatology from bed to bench, 5(1), 7.

Turner, G. S. (1964). Inactivation of vaccinia virus by ascorbic acid.Microbiology, 35(1), 75-80. http://dx.doi.org/10.1099/00221287-35-1-75

Van Damme, P., Banatvala, J., Fay, O., Iwarson, S., McMahon, B., Van Herck K. ... \& Leroux-Roels, G. (2003). Hepatitis A booster vaccination: is there need?. The lancet, 362(9389), 1065-1071. http://dx.doi.org/10.1016/s0140 6736(03)14418-2

Van Damme, P., Thoelen, S., Cramm, M., De Groote, K., Safary, A., \& Meheus, A. (1994). Inactivated hepatitis A vaccine: Reactogenicity, immunogenicity, and long-term antibody persistence. Journal of medical virology,44(4), 446-451. http://dx.doi.org/10.1002/jmv.1890440425

Vidor, E., Dumas, R., Porteret, V., Bailleux, F., \& Veitch, K. (2004). Aventis Pasteur vaccines containing inactivated hepatitis A virus: a compilation of immunogenicity data. European Journal of Clinical Microbiology and Infectious Diseases, 23(4), 300-309. http://dx.doi.org/10.1007/s10096-003-1094-0

Wang, C. H., Tschen, S. Y., Heinricy, U., Weber, M., \& Flehmig, B. (1996) Immune response to hepatitis A virus capsid proteins after infection. Journal of clinical microbiology,34(3), 707-713. http://dx.doi.org/10.1016/0264 410x(95)00152-q

White, L. A., Freeman, C. Y., Forrester, B. D., \& Chappell, W. A. (1986). In vitro effect of ascorbic acid on infectivity of herpesviruses and paramyxoviruses. Journal of clinical microbiology, 24(4), 527-531.

White, L. A., Freeman, C. Y., Forrester, B. D., \& Chappell, W. A. (1986). In vitro effect of ascorbic acid on infectivity of herpesviruses and paramyxoviruses. Journal of clinical microbiology, 24(4), 527-531.

Wu, D., \& Guo, C. Y. (2013). Epidemiology and prevention of hepatitis A in travelers. Journal of travel medicine, 20(6), 394-399. http://dx.doi.org/10.1111/jtm.12058

Zedan, M.A., Mohamed, F.A., Tantawy, H.M. \& Amal, S.M. (2003): Comparative Evaluation of different enhancers to liquid Rabies vaccine at different thermal conditions. Egypt. J. Zool., 40, 443-453. 